\title{
Hot adaptation: what conflict can contribute to collaborative natural resource management
}

\author{
David Laws $^{1}$, Daniel Hogendoorn ${ }^{2}$ and Herman Karl ${ }^{3,4}$
}

\begin{abstract}
We analyze the impact of conflict on the adaptive comanagement of social-ecological systems. We survey the risks and the resources that conflict creates and review experiences with public policy mediation as a set of practical hypotheses about how to work collaboratively under conditions of conflict. We analyze the significance of these features in the context of an approach to adaptive comanagement that we call "hot adaptation." Hot adaptation is organized to draw on the energy and engagement that conflict provides to enhance the capacity for deliberation and learning around the wicked problems that constitute the working terrain of adaptive comanagement.
\end{abstract}

Key Words: collaborative adaptive management; conflict resolution; emotion; public policy mediation

\section{INTRODUCTION}

"Conflict is the gadfly of thought. It stirs us to observation and memory. It instigates to invention. It shocks us out of sheeplike passivity, and sets us at noting and contriving.” John Dewey

"Whenever you're in conflict with someone, there is one factor that can make the difference between damaging your relationship and deepening it. That factor is attitude." William James

In this article, we explore the idea that adaptive comanagement practices that seek cool reason will often find the heat of conflict. We examine the roots of this heat in the central features of the problem and practice of adaptive comanagement and explore the risks that this central tension creates. We then turn to the contributions that the heat of conflict can make to the kind of sustained engagement and ability to deal with turbulent change that the adaptive comanagement of social-ecological systems demands. We conclude with a brief review of mediation as a practice that offers insights into how to manage the risks and get access to the benefits provided by the heat of conflict.

\section{CONFLICT AND COMANAGEMENT: LEARNING FROM THE HISTORY OF DEALING WITH ENVIRONMENTAL CONTROVERSY}

Most adaptive approaches to comanaging social-ecological systems share two commitments. The first is the recognition that management, in this context, is a dynamic process, driven by changes that are often abrupt and dramatic and that unfold under a persistent shadow of uncertainty. Olsson et al. (2006) draw on the metaphor of "shooting the rapids" to capture the "turbulent" conditions that management regimes face. Olsson et al. (2004:75) describe "learning how to deal with uncertainty and adapt to changing conditions" as "essential" features of governance regimes, in which human action and ecological dynamics are linked "from genetic levels to global scales." This, in turn, demands capacities for "dynamic learning" and for "sharing of management power and responsibility" (Olsson et al. 2004:75). These demands are not limited to coping with the dynamics of the ecological system, but spill over onto the social when "previous rules and social mechanisms ... no longer apply" (Olsson et al. 2006).
These insights inform a second commitment that is broadly shared: the groups and individuals that have stakes in these ecological systems should be involved in making decisions about their management. The demands of dealing with uncertainty and change make comanagement regimes "reli[ant] on networks that connect individuals, organizations, agencies, and institutions at multiple organizational levels" (Olsson et al. 2006). The rationale for stakeholder involvement is practical and extends beyond acknowledging that stakeholders often have the power to block or delay the implementation of management decisions. The commitment to involve stakeholders also recognizes that "knowledge of ecosystem dynamics and associated management practices exists among people of communities that, on a daily basis and over long periods of time, interact for their benefit and livelihood with ecosystems" (Folke et al. 2005:445-446).

Involving stakeholders changes the problem that management regimes must cope with, however. Stakeholders bring more than relevant knowledge about "uncertainty, complexity, and substantial biophysical constraints" to the table (Dietz et al. 2003:1907). Their involvement makes "conflicting human values and interests" part of the challenge that management regimes face (Dietz et al. 2003:1907). Information about changing ecological conditions will be filtered through, and will become mixed with, social, economic, and political relationships, as stakeholders contemplate questions about when and how to act. Conversely, their actions will influence the dynamics of natural systems, and the possibility of regulating their behavior will be a core question in the development of management regimes.

These two commitments are thus not independent. Their interaction shapes the possibilities for management practices that can cope with uncertainty and sudden change and with the multiple and deeply rooted ways in which stakeholders are integrated with ecological systems. The story with which Brunner and Steelman (2005) open their edited volume on adaptive governance captures the way these features interact. The opening scene unfolded on 4 July 2001 in Klamath Falls, Oregon. A group of protestors was gathered around the headgates of an irrigation canal that the U.S. Bureau of Reclamation had closed three months earlier, effectively shutting down irrigation in the midst

\footnotetext{
${ }^{1}$ University of Amsterdam, ${ }^{2}$ Technical University of Delft, ${ }^{3}$ Visting Research Faculty, Antioch University New England, Keene, New Hampshire,

${ }^{4}$ Affiliate Associate Professor, University of New Hampshire
} 
of a drought. The protestors carried signs saying, "How can you destroy my future?" as they screened from view their coconspirators, who were working with torches and crowbars to reopen the contested gates and release water for irrigation (Bruner and Steelman 2005:1-2). No public official interfered.

The dispute was, at one level, a technical controversy about the effect that water levels in the Upper Klamath Lake would have on the survival of species of fish and wildlife that were protected under the Endangered Species Act. For the farmers, feed and fertilizer salesmen, hairdressers, and grocers who depended, directly or indirectly, on irrigation from Klamath Lake for their livelihoods, the technical controversy was also a question about economic survival and about the continuity of a way of life. The Bureau's proposals linked to residents' views of themselves as citizens and neighbors, their relationship to government, their sense of fair play, and their expectations about the future. Much the same could be said for the environmental advocates, who took an opposing position on water levels out of concern for the protection of endangered fish and wildlife and concern for the Native Americans whose lives and livelihoods would be affected by the water management decisions.

The technical dispute immediately became rooted in the everyday lives of stakeholders. Comments like "It feels like our freedom is being betrayed" or "I'm tired of playing by the rules. Nobody's listening," and "The Bureau totally betrayed us" reflect the level at which the dispute fostered distress and engaged identities and expectations (Brunner and Steelman 2005:1, 6). The increased demands that the local food bank and mental health services experienced reflect the depth to which the controversy cut the fabric of the community (Brunner and Steelman 2005).

The conflict in Oregon is not an isolated example. In Tomales Bay, California, disputes over water quality have shaped relationships among ranchers, oyster farmers, and conservation advocates for over a century. These disputes anchor a history of threat, against which contemporary plans and actions are read. On Cape Cod in Massachusetts, a dispute over protecting an endangered species of shorebird quickly became a conflict between working class locals and summer residents, who were divided by history, by interests, by economic prospects, and by their views of the future. Issues about natural resources invariably raise memories and aspirations rooted in work, family, and community. As distinct as technical concerns might seem from these considerations, the history of environmental conflict suggests that they will come into play when practical decisions about managing social-ecological systems play out in concrete settings and affect the lives of citizens (Susskind and McKearnan 1999). The actions the citizens take will make their concerns a tangible part of the experience of the public officials and technical advisors who share formal responsibility for managing these systems. There is, in short, no escape to a "view from nowhere" (Nagel 1989).

A significant potential for disruption arises when such concerns are brought into focus by sudden and dramatic changes in ecological systems. Changes in water management in the Klamath Basin, for example, disrupted the stable relationships that shaped views about the future in the farming community. Farmers whose expectations were grounded in a stable history in which water flowed and farming thrived suddenly faced the question, "What is going on here?" It arose "explicitly ... in [this] time ... of confusion and doubt" even though it had been present in the background throughout the preceding period (Goffman 1986:8). The question, erupting in this way, upset the prevailing balance between the "struggle to attain a state of belief" and the "irritation of doubt" (Peirce 1992:114). It triggered an effort to reestablish certainty by contesting the new policy.

Framing provides a practical way to grasp the dynamics that unfold when such questions arise in moments of controversy (Schön and Rein 1995, Lewicki et al. 2002, Laws and Rein 2003, Hajer and Laws 2006). The individuals and groups whose expectations are disrupted struggle to make sense of what is going on in their community. Framing describes this sense-making as a process of selecting "some aspects of a perceived reality and mak [ing] them more salient ... Frames ... define problems, ... diagnose causes, ... make moral judgments, ... and suggest remedies ..." (Entman 1993:52). Framing describes sense-making as the process of drawing relationships among these features of experience; "the frame is the internally coherent constellation of facts, values, and action implications" that settles belief (Hajer and Laws 2006:257). This process of drawing relationships depends on the set of historical experiences and current concerns, the "prospect," from which stakeholders confront a situation (Kahneman and Tversky 1981). Even statements as basic as risk preferences have been shown to be mutable with a shift in this prospect, say, from seeing available options as a potential benefit to seeing them as an imposed cost (Kahneman and Tversky 1981). Thus framing helps us grasp the dynamics that will be created when stakeholders with thick and complex ties to ecological systems experience sudden changes that have the potential to impact their welfare and identity.

This has direct implications for conflicts over the management of dynamic social-ecological systems. Problem definitions, causal interpretations, and moral evaluations are likely to coalesce as judgments about action, rather than build in a managed, logical sequence. Moreover, framing takes shape early; stakeholders will come to a controversy already having interpreted the situation. The sort of learning and development connoted by cooperation, collaboration, and comanagement will involve changing established frames rather than creating new ones. Stakeholders will select and give salience from positions that have distinct social, economic, and historical antecedents. The net result is that the practical demands of sense-making make difference unavoidable and active in conflicts. A farmer or fisherman whose livelihood and family are at risk cannot be expected to set these concerns aside; they will be integrated into the way he or she frames events and reasons about how to act. Management practices must find a way to cope with the diverse reasonable views that are anchored in the divergent framings and cope with the differences to which this diversity gives rise.

Other facets of conflict and controversy make the management of social-ecological systems even more challenging. Because changes will often be abrupt, uncertainty high, and risks tangible, perceptions of threat can be expected to play a role in the way framing develops. The very events that provide information about changes in the ecological system will also impact stakeholders' lives and futures in tangible ways. The impacts may be economic, rooted in family or in community, or, most likely, in some 
combination of these features. Farmers in Klamath Falls and ranchers in Tomales Bay felt the impact of management decisions as a threat to their economic prospects, to their families, and to their local way of life. Questions about what sort of practical arrangements for managing the Bay would be fair, effective, and appropriate were read through these threats.

The prevalence of these perceptions of threat in the initial stages of conflict has an important effect on how relationships develop and action unfolds. Social psychologists speak of conflict behavior as a choice among four generic action strategies: avoiding, conceding, contending, and problem-solving (Pruitt et al. 2004). Stakeholders who feel that management decisions are being imposed will rule out avoiding as a viable option. Problem solving demands a shared commitment to openness and a confidence in working relationships that may be hard to create under the weight of threat, particularly when people can point to prior experiences in which they felt marginalized. This can leave stakeholders with a choice between conceding, and so accepting whatever comes their way, and contending. The choice is easily seen as part of a zero-sum struggle in which contending is the only option that offers the hope of protecting cherished values. Contentious tactics can, thus, serve fear and anger as well as greed, protecting us against external threats as well as advancing our interests at the expense of others (De Dreu et al. 2010).

In Tomales Bay, for example, ranchers came into conflict with fishing and conservation interests over their historical practice of damming streams on tidal wetlands to provide water for livestock during summer droughts. Fishers and conservation groups attacked the practice. In a prominent case, fishers lobbied the U. S. Army Corps of Engineers to revoke its permission for a dam on Lagunitas Creek on the grounds that the practice degraded the fish habitat and failed to provide the required bypass for fish to migrate upstream (Avery 2009). The ranchers defended, and soon both sides were committed to tactics that expressed and confirmed expectations that they were involved in a zero-sum struggle.

Avery (2009:163) noted, "The issue grew contentious at public meetings. Although the Tomales Bay Sportsman's Association, the Marin County Farm Bureau, and most Tomales Bay area ranchers supported the Giacominis, fishermen collected 1285 signatures from people opposed to the dam. The Army Corps of Engineers stopped issuing permits for the Giacominis' summer dam in 1997 due to concerns about fish habitat ... Many ranchers believed that this incident proved that agriculture and the new emphasis on ecological restoration and environmental protections were incompatible."

When opposing stakes in a zero-sum game and divergent or "biased" perceptions, features of conflict, come together with a final factor, "processes of commitment rising out of social and cognitive pressures for consistency," they enhance the possibility that the conflict will take a destructive turn (Deutsch 1977:352). Pressures for consistency are common. Individuals will often adjust their beliefs to be consistent with their actions, and their actions to conform to their peers, rather than the other way around, and will disproportionately seek out information that confirms the validity of their actions (Kunda 1999). Social pressures such as group solidarity enhance these cognitive pressures for consistency. Deutsch (1977) demonstrates how early steps, such as the defensive reflex to protect a historical practice like building dams against external challenges, can commit a group to a course of action that they will justify when pressured in subsequent action. These justifications will further deepen their commitment and deepen the divide that separates them from groups with opposing views.

Escalation is the well-established pattern that develops when these features reinforce one another in a downward spiral of action and reaction. As people experience events, they apply positive, or, in these cases, negative values that become a "conditioned reinforcement" (Panksepp and Panksepp 2001). The result is that even situations that may seem benign to outsiders are perceived as threatening. Initial skepticism about the claims and views of the other, e.g., "How could they say such a thing," creates early commitments to positions that provide each side with evidence that cherished values need to be defended (e.g., "See, I told you they were out to get us"). A focus on winning develops that, in the context of pressures for consistency, makes it difficult for either side to back down. Soon the only path open is to employ ever harder, more contentious tactics to win the struggle. The move to facts often only deepens the divide and reconstitutes the fight as a battle of experts (Karl et al. 2007). Structural changes such as a shift to tougher representation, the deterioration of communication, and demonization of the other (e.g., "You just can't talk with them") lock in the pattern and make it ever more difficult to shift direction (Pruitt et al. 2004). The potential for escalation is created by the interplay among common unavoidable features of the settings in which natural resource management plays out. It is the 800-pound gorilla in the room whenever conflict flares up. Any effort to understand conflict in these settings and to draw on it as resource must account for the threat that escalation poses and the ease with which it can take hold.

These features, namely, the layering of economic, social, and historical features with technical aspects of resource management; the interweaving of these features in the process of framing; the perceptions of threat that can lead to a preference for contentious tactics; and the self-confirming dynamics of escalation that unfold when such tactics are employed, are wellestablished aspects of conflict that any effort to grasp the role of conflict in adaptive comanagement must address. Overall, they suggest that the practical choice may not be between having conflict and avoiding it, but between contentious and constructive ways to engage the conflicts that are inevitable when complex ecological dynamics interact with diverse human interests and identities, and with historically rooted practices.

The history of environmental conflict has been punctuated by episodes in which advocates for competing views have turned their passion and engagement into both destructive and constructive patterns of interaction. Brunner and Steelman (2005:2) describe how conventional practices have heightened conflict, and note that: "in recent decades, with the proliferation of organized groups, the remnants of scientific management have done more to exacerbate than to resolve conflicts over natural resources." Others describe how alternative practices like negotiation and mediation have provided "a means of avoiding protracted court battles over actual or potential environmental degradation" (Susskind and McKearnan 1999:98, Forester 2009, Innes and Booher 2010). 
The significance of these experiences has not been lost on those who practice and study adaptive comanagement. Arnold et al. (2012) highlight the power asymmetries and conflicts that shape multistakeholder processes, and the difficulty that practitioners experience when they try to meaningfully separate stakeholders' interests from the natural resources to which they are bound. In their view, these features make capacity building and system management internally complex and underscore the need to involve stakeholders. Conflict remains something to be avoided, however, even as managers struggle to be more critical in their interactions with experts and more open in their relationships with stakeholders.

Cundill et al. (2012) go a step further and reflect explicitly on the experience of dealing with conflict in the comanagement of socialecological systems. They focus on working assumptions about how stakeholders set goals, make decisions, and act on decisions that, in their view, have proven to be problematic. The assumption that "planning is an objective process in which scientists and policy makers are neutral actors" is an example of the kind of commitment that distorts management practices, especially if it is taken to imply a contrast with subjective and self-interested stakeholders or to suggest that natural-resource managers somehow work from a position outside the system, rather than from inside the system and with a stake (Nozick 2001, Cundill et al. 2012:14). Cundill et al. (2012) conclude that theorists and practitioners have given too little attention to the subtle variations in working practices that define decision-making processes and too little attention to designing questions about who should be engaged, when, and how. They suggest that we give more attention to how shared frames develop, to how local stakeholders behave, and to how reflection on these questions develops under conditions of controversy. A "key research question during these activities is to what extent any conflict or disagreement created by introducing new knowledge and alternative values and worldviews can stimulate learning, creativity, and change" (Cundill et al. 2012:17).

We treat this question as a central concern for both practitioners and researchers. We examine the proposal that conflict, under certain conditions, can lead to a deeper engagement with the facts, the people, the dynamics, and the uncertainties that matter and so stimulate learning, innovation, and development. We turn in the conclusions to public policy mediation as one source of practical insight into what conditions might foster such engagement and learning. It is our hope that this analysis will contribute to the development of forms of adaptive management that can draw on the dynamics of conflict as a resource in the effort to cope with uncertainty and will address the technical and moral complexity defines social-ecological systems.

\section{CONFLICT AS AN OPPORTUNITY AND A RESOURCE}

A growing body of research and practical experience suggests that "hot" forms of interaction, in which the participants have detailed historical knowledge of the issues and a direct stake in the outcome, can enhance the quality of practical deliberation and decision making. We briefly sketch two such contributions: (i) the way in which so-called "biased positions" and "negative emotions" can help create and sustain the kind of engagement that complex systems demand and (ii) the way in which conflict can help structure interaction by "organizing the opponent."
Each, with downsides managed, can contribute the quality of the decision making.

Funtowicz and Ravetz (1991) suggest a place to begin. They put a twist on the NIMBY (not in my backyard) perspective that often dominates opinions about the prospects for local engagement in complex choices about policy and management. In their view, local engagement is not only an unavoidable feature of practical decisions, but also is a resource that can enhance the quality of practical deliberation.

They note: "It is important to realize that the need for enriched input is not merely the result of the external political pressures on science that occur when the general public is concerned about some issue.... When problems do not have neat solutions, when the phenomena themselves are ambiguous, when all mathematical techniques are open to methodological criticism, then the debates on quality are not enhanced by the exclusion of all but the academic or official experts. Knowledge of local conditions may not merely shape the policy problems, it can also determine which data is strong and relevant. Such knowledge cannot be the exclusive property of experts whose training and employment inclines them to abstract, generalized conceptions. Those whose lives and livelihood depend on the solution of the problems will have a keen awareness of how general principles are realized in their 'backyards.' It may be argued that they lack theoretical knowledge and are biased by self-interest; but it can equally well be argued that the experts lack practical knowledge and have their own forms of bias... Let us be quite clear on this: we are not calling for the democratization of science out of some generalized wish for the greatest possible extension of democracy into society ... [Analysis of the] practical tasks of quality assurance shows that such an extension of peer communities ... is necessary for the effectiveness of this new sort of science in meeting the challenges of global environmental issues" (Funtowicz and Ravetz 1991:149-151, emphasis added).

In short, the kind of scrutiny people give to what is going on in their backyards is an important and valuable contribution to the quality of decisions. The sustained attention helps to pool information and distill appropriate knowledge. The engagement of local stakeholders will also bring in social, economic, and political dimensions. The emotions that accompany these dimensions may appear to complicate efforts to analyze the dynamics of social-ecological systems.

Research increasingly presents a contrasting view. Emotions are seen as central to perception, cognition, interaction, and imagination and thus to deliberation and decision making (Panksepp 1998). Emotions contribute to, rather than detract from, affected parties' capacity to perceive and to reason together. Peters et al. (2006), for example, summarize four useful roles for affect in decision making: as a source of information, as "common currency" that allows those involved to relate different kinds of events and experiences (including future benefits and losses), as a "spotlight" that highlights the significance of new information, and as a way to establish and maintain a positive mood. Social emotions help bonds develop, which facilitate coordination (Panksepp 1998).

It is relatively easy to imagine positive roles for "positive" emotions, such as the seeking emotions associated with problem 
solving. The kinds of affect that people associate with conflict, such as anger, can also enhance engagement and deliberation, however. Emotions associated with conflict are, for example, a sign that a person believes an issue is significant, highlighting central, even existential, interests and deeply held beliefs; they may reflect a willingness to commit more deeply to a process (Pfister and Böhm 2008). The heat generated by contentious issues may help to bring groups into the relationships that can produce the sustained capacity for monitoring, accountability, and deliberation that is essential to meet the demands posed by adaptive comanagement. Others have pointed to the way anger, fear, and panic function in judging risks and, consequently, can provide insight into what people think should be avoided (Peters et al. 2005; Böhm and Brun 2008). Although some risks may require the subjective risk estimate of the professional expert, many risks are accurately signaled through the emotions expressed by those with direct experience in a local setting. Anger, moreover, is the emotion associated with the tie between a sense of purpose and a perceived injustice; it can facilitate the assessment of the validity of arguments not just on the basis of truth, but also on the basis of fairness (Panksepp 1998). Anger expresses moral indignation, but also contributes to scrutiny of other parties' reasoning (Haidt 2012). Conflict can thus contribute to adaptive learning by challenging the embedded assumptions that are part of any developed frame, including those of experts and professionals (Schön 1983, Laws and Rein 2003). Given the ease with which we generate arguments that confirm our prior values, interactions with committed opponents may be needed to recognize flaws in our own reasoning and to counter the confirmation bias and groupthink that plague any organizational process (Mercier and Landemore 2012).

There are, of course, also risks. Anger and contentious tactics tend to block emotions associated with invention and problem solving (Panksepp 1998). However, if anger is met with stonewalling, the seeking emotions associated with problem solving may become chronically understimulated, generating apathy (Panksepp 1998). Thus, both ignoring and blocking anger will deprive decision-making processes of the benefits of engagement and will divert it to other channels of expression. Much depends on the ability to manage the heat generated by the open-ended "wicked" problems that are at the heart of many environmental controversies. What is needed are channels in which affect is not just vented, but in which it contributes to "moral knowledge," the "highly context-specific and nuanced and responsive seeing" that is necessary to make sense of "a complex, concrete reality in a highly lucid and richly responsive way; ... taking in what is there, with imagination and feeling" (Nussbaum 1992:152).

A second virtue of conflict is its organizational effects. Organizing the opposition may seem counterintuitive; its virtues become clear, however, when it is compared to the alternative: facing unorganized opposition that cannot be engaged, that continually shifts demands and tactics, and that cannot credibly make or keep commitments. Moreover, sustained engagement demands sufficient organization among stakeholders for their representatives to participate in deliberations over management.

The ability of conflict to bind groups has been recognized for some time. Even "conflicts of interest arising from purely instrumental considerations of 'isolated individuals' have had the unanticipated consequences of creating groups and associations that overcome the ... isolation of the individual... By giving rise to temporary associations, conflict can bring the various elements of society together. It leads to concerted action and gives form and order to ... 'a dust of individuals."' (Coser 1956:141). Collective action in resisting a policy can provide the kernel for the kind of "resistance identity" that can be quite powerful in drawing groups together and in sustaining association (Castells 1997).

Analysis of the organizational effects of conflict has underscored that it is often much easier to deal with an organized group than a disorganized one. Coser (1956:130-131) illustrates these advantages from the history of union-management relations, quoting Samuel Gompers (1920): "We welcome the organization of the employers. We know one thing, that when there is organization founded upon a rational basis there is a greater tendency to agreement between the employers and the employed." Such pragmatic marriages of convenience formed in resistance provide a kind of organizing and prioritizing function for interests that may make it easier to engage opponents. Associations that start out as purely instrumental may also develop into more enduring forms that can take on the kind of ongoing engagement that adaptive comanagement demands. A third feature extends the significance of this group-binding function. Unless conflict is aimed at annihilation, it creates a relationship where none may have existed and "gives rise to regulations and norms governing its conduct and restraining the forms in which it is being fought" (Coser 1956:121). Conflict may, thus, provide a means to " 'test' and 'know' the previously unknown" and "thus often leads to subsequent friendly interaction" (Coser 1956:122-123). As these interactions invoke and give shape to "a common universe of norms and rules," the very effort to dispute the meaning of these norms and their practical force in the case at hand will acknowledge that shared principles exist (Coser 1956:122-123).

If we combine the organizational aspects, the potential for development, and the acknowledgement of shared rules and norms, we can see how conflict might lead to the creation of a case-based "minipublic" (Fung 2003). The development and capacities of minipublics are relevant to the extent that collaborative adaptive management requires an active public sphere. In conditions of political and cultural fragmentation, an organized and coherent public may be hard to find. Minipublics may provide a practical alternative whose virtues include "political education [and] social solidarity" that link directly with concerns for legitimacy and extend "to include public accountability, social justice, effective governance, and popular mobilization," all capacities that are directly relevant for adaptive comanagement (Fung 2003:339-340). Thus minipublics may provide a practical and attractive alternative that can develop around the controversial problems that arise in the comanagement of social-ecological systems. This is particularly significant where the wicked character of problems pushes management beyond technical solutions and a "continuous and symbiotic relationship between the state and the public sphere" is essential for addressing the shared problems (Fung 2003:341).

\section{CONCLUSION: PRACTICING HOT ADAPTATION}

We described how the potential for conflict and escalation arises from core features of social-ecological systems. The heat generated when stakeholders with diverse stakes and historical 
perspectives encounter one another under conditions of sudden change and threat raises risks and creates resources that adaptive comanagement regimes would be wise to draw on. We turn now to a practitioner's take and briefly review a set of hypotheses about how to manage the risks posed by conflicts and how to get access to the virtues it might provide. These hypotheses are expressed in practical terms as designs for engaging stakeholders through public policy mediation and mediated consensus building. Together they provide a practical view of the sequence through which hot adaptation might take shape in concrete settings. To be clear, mediation is one approach in a rapidly developing repertoire of designs for engaging the public (Gastil and Levine 2005, Fung 2006). We focus on public policy mediation because of its stakeholder orientation, because of the close association it has had historically with environmental conflict, and because of the successes in building collaboration that are part of this experience. We try to bring out the hypotheses about managing conflict that are embedded in the design of mediated consensus building and highlight their implications for developing hot forms of adaptive comanagment.

Public policy mediation, or mediated consensus building, is an approach to stakeholder involvement that, when it works, allows the parties to have their conflict and turns their passion toward constructive ends (Podziba 2013). It is distinguished by the following features:

- the direct involvement of the stakeholders affected by policy and management choices;

- these stakeholders' ability to collectively set internal ground rules, frame goals, and develop (and negotiate) proposals and plans;

- the consensus rule by which these processes operate;

- the active involvement of the sponsoring agency in the deliberations and negotiations and its commitment to act on the outcomes if consensus (including the assent of the public agency) can be reached;

- the involvement of a mediator to help organize and manage the negotiations.

We organize our review on the basis of the sequence of stages through which mediated consensus building is commonly described (Susskind et al. 1999, Forester 2009). This perspective reflects the way practitioners approach a case and highlights the developments that stakeholders go through when they begin with divergent experiences, varying degrees of trust, and skepticism about possibilities for cooperation, and end with practical consensus on a plan for taking action. The sequence moves from conflict assessment to convening, to learning through joint factfinding, to negotiation, which, when it produces consensus, leads to implementation.

Conflict assessment is a diagnostic effort to weigh the feasibility of organizing a formal mediation process. A conflict assessment is conducted by an individual who is accepted by all stakeholders as independent and who has the capacity to mediate the negotiations if a decision is made to move forward. Assessment is based on individual interviews that allow the assessor to learn about the subjective experience and interests of each stakeholder group and the way it has framed the conflict. Assessment provides a working map of the experiences, needs, concerns, and goals that constitute the conflict for the stakeholders. A good assessment report will capture these views so that each stakeholder recognizes its story, and it will situate the stories so that stakeholders are all pushed to recognize the legitimacy of the stories that others have told. For resource managers who face a conflict, assessment provides a relatively low-risk way to assess the feasibility of mediation and other options and the demands of money, time, etc., that each option would put on their organization. Finally, it provides a mechanism to start to break down mistrust and build the relationships that will be needed if the group is to work together constructively in a shared effort to build consensus.

If a decision is made to move forward, the next step is convening. Formally, convening is the process that brings the stakeholders together as a group with a specific charter. It establishes the government sponsorship and the involvement of the stakeholders with each other and with the problem or question that provides the starting point. During convening, stakeholders take over control of the process and acknowledge their interdependence and provisional commitment to work together. The practical hypothesis is that negotiating ground rules, goals, and an agenda will trigger a process of bootstrapping that will eventually make constructive negotiations plausible to those involved. The challenges posed by convening will cut especially deep for the government sponsors of the process, who will go from being the responsible party with authority to act, to being one of a group of stakeholders that shares responsibility. This does not mean giving up influence or control, but it does mean that these will be expressed at the table as views of a powerful negotiator that interacts with other stakeholders.

Public policy mediation seeks to produce not just agreements, but agreements that are informed by the best analysis possible. Because of the uncertainty and ambiguity that wicked problems involve, technical analysis is unlikely to be dispositive, however. Thus, the first step following convening is usually a stage in which stakeholders try to learn about the problem together. In this joint fact-finding, stakeholders seek to learn together about the key features of the problem, about each other's experience, about any technical constraints, and about the moral and political obligations that they feel. Joint fact-finding is rooted in the hypothesis that learning develops when stakeholders become involved in a shared exploration of the margins and limits of their understanding and the key questions that must be answered to reason about how to act (Laws and Forester 2007). In this way, the battle of experts that often evolves in conflicts can be replaced by a constructive form of dialogue (Karl et al. 2007). This highlights a second working hypothesis: that progress can often be made in contentious circumstances by focusing on how to get on with the situation at hand rather than on whose assertions are true or whose science is right. For resource managers, the ability to move forward in the face of uncertainty and controversy may be an attractive option.

This learning opens onto a process of negotiation, in which stakeholders work to design a plan that each representative can accept because it is better for her constituency than alternatives 
that are available to them. The working assumption is that focusing on the distinct needs, interests, and concerns of stakeholders, including public agencies and advocacy groups, will be more likely to lead to a workable agreement than will an effort to specify and assert a general public interest. Such negotiation works by “acknowledging each other's needs as well as your own and making proposals that respond to both. Arguing that you don't like what the other wants and want something else instead (the old style of bargaining) doesn't produce agreement," L. Susskind observed in Forester (1994:343).

Negotiation of this kind involves two related hypotheses. The first is that rooting negotiation in stakeholders' distinct needs, interests, and concerns will open an exploration of interdependence that will naturally lead stakeholders to consider common interests and broader responsibilities. This will be enhanced when parties explore innovative options for action. The second hypothesis is that creating a plan that all stakeholders prefer to the available alternatives is a goal that can be met in many cases (Susskind and Cruikshank 1987). Negotiation is the vehicle for grasping interdependence and giving it shape in practical options for action. It offers managers a procedural option that treats stakeholders with respect and engages their creativity to help fashion a practical design that they are all willing to commit to and to publicly support.

When this sequence of stages works, it sets the conditions for effective implementation. The hypothesis is that when stakeholders have played an active role in ensuring that their interests and concerns are addressed, they will be less likely to obstruct plans. Adaptive comanagement provides a context to explore when and under what conditions this kind of support can be extended to taking active roles in monitoring implementation and renegotiating initial agreements in light of emerging experience.

We have argued that conflict is an almost unavoidable feature of managing social-ecological systems that are valued and used by diverse groups of stakeholders. We have summarized some of the features that make conflict unavoidable and the core risks that managers should understand. We have also tried to highlight the resources that conflict offers for improving practical deliberations about management and for sustaining the engagement of affected stakeholders. We hope that this analysis will contribute to the development of hot forms of adaptive management. Our reading of the history of dealing with environmental conflict suggests that such hot adaptation will be characterized by the direct involvement of stakeholders in making sense of problems, in designing practical responses, and in monitoring the implementation of these plans. The heat of conflict can contribute to the active engagement of stakeholders who are willing to challenge habits of thought and action and whose emotion and commitment can inform and sustain a process of moral and practical learning.

Responses to this article can be read online at: http://www.ecologyandsociety.org/issues/responses. $\mathrm{php} / 6375$

\section{Acknowledgments:}

The authors wish to thank Howard Bellman, John Forester, Maarten Hajer, Martien Kuitenbrouwer, Arthur Petersen, Suzan Podziba, Alexander Rinnooy Kan, Larry Susskind, and the spirited and committed thinkers on Nassim Taleb's Facebook page for ongoing conversations and reflections on this topic.

\section{LITERATURE CITED}

Arnold, J. S., M. Koro-Ljungberg, and W.-L. Bartels. 2012. Power and conflict in adaptive management: analyzing the discourse of riparian management on public lands. Ecology and Society 17(1): 19. http://dx.doi.org/10.5751/ES-04636-170119

Avery, C. 2009. Tomales Bay environmental history and historic resources study. Pacific West Region, National Park Service, U.S. Department of Interior.

Böhm, G., and W. Brun. 2008. Intuition and affect in risk perception and decision making. Judgment and Decision Making $3(1): 1-4$.

Brunner, R. D., and T. A. Steelman. 2005. Beyond scientific management. Pages 1-46 in R. D. Brunner, T. A. Steelman, L. Coe-Juell, C. M. Cromley, C. M. Edwards, and D. W. Tucker, editors. Adaptive governance: integrating science, policy, and decision making. Columbia University Press, New York, New York, USA.

Castells, M. 1997. The power of identity. Blackwell, Oxford, UK.

Coser, L. 1956. The functions of social conflict. Free Press, Glencoe, Illinois, USA.

Cundill, G., G. S. Cumming, D. Biggs, and C. Fabricius. 2012. Soft systems thinking and social learning for adaptive management. Conservation Biology 26(1):13-20. http://dx.doi. org/10.1111/j.1523-1739.2011.01755.x

De Dreu, C. K. W., L. L. Greer, M. J. J. Handgraaf, S. Shalvi, G. A. van Kleef, M. Baas, F. S. ten Velden, E. van Dijk, and S. W. W. Feith. 2010. The neuropeptide oxytocin regulates parochial altruism in intergroup conflict among humans. Science 328 (5984):1408-1411. http://dx.doi.org/10.1126/science.1189047

De Sousa. 1987. The rationality of emotion. MIT Press, Cambridge, Massachusetts, USA.

Deutsch, M. 1977. The resolution of conflict: constructive and destructive processes. Yale University Press, New Haven, Connecticut, USA.

Dietz, T., E. Ostrom, and P. C. Stern. 2003. The struggle to govern the commons. Science 302(5652):1907-1912. http://dx.doi. org/10.1126/science.1091015

Entman, R. M. 1993. Framing: toward clarification of a fractured paradigm. Journal of Communication 43(4):51-58. http://dx.doi. org/10.1111/j.1460-2466.1993.tb01304.x

Folke, C., T. Hahn, P. Olsson, and J. Norberg. 2005. Adaptive governance of social-ecological systems. Annual Review of Environment and Resources 30:441-473. http://dx.doi.org/10.1146/ annurev.energy.30.050504.144511 
Forester, J. 1994. Lawrence Susskind: activist mediation and public disputes. Pages 309-358 in D. Kolb, editor. When talk works. Jossey-Bass, San Francisco, California, USA.

Forester, J. 2009. Dealing with differences: dramas of mediating public disputes. Oxford University Press, Oxford, UK.

Fung, A. 2003. Survey article: recipes for public spheres: eight institutional design choices and their consequences. Journal of Political Philosophy 11(3):338-367. http://dx.doi. org/10.1111/1467-9760.00181

Fung, A. 2006. Varieties of participation in complex governance. Public Administration Review 66:66-75. http://dx.doi.org/10.1111/ j.1540-6210.2006.00667.x

Funtowicz, S. O., and J. R. Ravetz 1991. A new scientific methodology for global environmental issues. Pages 137-152 in Robert Costanza, editor. Ecological economics: the science and management of sustainability. Columbia University Press, New York, New York, USA.

Gastil, J., and P. Levine, editors. 2005. The deliberative democracy handbook. Wiley, San Francisco, California, USA.

Goffman, E. 1986. Frame analysis: an essay on the organization of experience. Northeastern University Press, Boston, Massachusetts, USA.

Haidt, J. 2012. The righteous mind. Why people are divided in politics and religion. Pantheon Books, New York, New York, USA.

Hajer, M. 2009. Authoritative governance. Policy making in the age of mediatization. Oxford University Press, Oxford, UK. http://dx. doi.org/10.1093/acprof:oso/9780199281671.001.0001

Hajer, M., and D. Laws. 2006. Ordering through discourse. Pages 249-266 in M. Moran, M. Rein, and R. E. Goodin, editors. The Oxford handbook of public policy. Oxford University Press, London, UK.

Innes, J. E., and D. E. Booher. 2010. Planning with complexity: an introduction to collaborative rationality for public policy. Routledge, Milton Park, UK, and New York, New York, USA.

Kahneman, D., and A. Tversky. 1981. The framing of decisions and the psychology of choice. Science New Series 211 (4481):453-458.

Karl, H. A., L. E. Susskind, and K. H. Wallace. 2007. A dialogue, not a diatribe: effective integration of science and policy through joint fact-finding. Environment 49(1):20-34. http://dx.doi. org/10.3200/ENVT.49.1.20-34

Kunda, Z. 1999. Social cognition: making sense of people. MIT Press, Cambridge, Massachusetts, USA.

Laws, D., and J. Forester. 2006. Public policy mediation: from argument to collaboration. Page 513-524 in F. Fischer, G. J. Miller, and M. Sidney, editors. Handbook of public policy analysis: theory, politics, and methods. Taylor and Francis, New York, New York, USA.

Laws, D., and J. Forester. 2007. Learning in practice: public policy mediation. Critical policy studies 1(4):342-370. http://dx.doi. org/10.1080/19460171.2007.9518526
Laws, D., and M. Rein. 2003. Reframing practice. Pages 172-206 in M. Hajer and H. Wagenaar, editors. Deliberative policy analysis: understanding governance in the network society. Cambridge University Press, Cambridge, UK. http://dx.doi.org/10.1017/ CBO9780511490934.008

Lewicki, R., B. Gray, and M. Elliott, editors. 2002. Making sense of intractable environmental conflicts: concepts and cases. Island Press, Washington, D.C., USA.

Mercier, H., and H. Landemore. 2012. Reasoning is for arguing: understanding the successes and failures of deliberation. Political Psychology 33(2):243-258. http://dx.doi.org/10.1111/ j.1467-9221.2012.00873.x

Nagel, T. 1989. The view from nowhere. Oxford University Press, Oxford, UK.

Nozick, R. 2001. Invariances: the structure of the objective world. Belknap Press of Harvard University Press, Cambridge, Massachusetts, USA.

Nussbaum, M. 1992. Love's knowledge. Oxford University Press, Oxford, UK.

Olsson, P., C. Folke, and F. Berkes. 2004. Adaptive comanagement for building social-ecological resilience. Environmental Management 34:75-90. http://dx.doi.org/10.1007/s00267-003-0101-7

Olsson, P., L. H. Gunderson, S. R. Carpenter, P. Ryan, L. Lebel, C. Folke, and C. S. Holling. 2006. Shooting the rapids: navigating transitions to adaptive governance of social-ecological systems. Ecology and Society 11(1): 18. [online] URL: http://www. ecologyandsociety.org/vol11/iss1/art18/

Panksepp, J. 1998. Affective neuroscience: the foundations of human and animal emotions. Oxford University Press, Oxford, UK.

Panksepp, J., and J. P. Panksepp. 2001. A continuing critique of evolutionary psychology: seven sins for seven sinners, plus or minus two. Evolution and Cognition 7:56-80.

Peirce, C. S. 1992. The fixation of belief. Pages 109-123 in N. Houser and C. Kloesel, editors. The essential Peirce: selected philosophical writings. Volume 1. Indiana University Press, Bloomington, Indiana, USA.

Peters, E., D. Västfjäll, T. Gärling, and P. Slovic. 2006. Affect and decision making: a 'hot' topic. Journal of Behavioral Decision Making 19:79-85. http://dx.doi.org/10.1002/bdm.528

Pfister, H.-R., and G. Böhm. 2008. The multiplicity of emotions: a framework of emotional functions in decision making. Judgment and Decision Making 3(1):5-17.

Podziba, S. 2013. Civic fusion: mediating polarized public disputes. American Bar Association Publishing, Chicago, Illinois, USA.

Pruitt, D., J. Rubin, and S. H. Kim. 2004. Social conflict: escalation, stalemate, and settlement. Third edition. McGrawHill, New York, New York, USA.

Schön, D. A. 1983. The reflective practitioner: how professionals think in action. Basic Books. New York, New York, USA. 
Schön, D., and M. Rein. 1995. Frame reflection: toward the resolution of intractable policy controversies. Basic Books, New York, New York, USA.

Susskind, L., and J. Cruikshank. 1987. Breaking the impasse. Basic Books, New York, New York, USA.

Susskind, L., and S. McKearnan. 1999. The evolution of public policy dispute resolution. Journal of Architectural and Planning Research 16(2):96-115.

Susskind, L., S. McKearnan, and J. Thomas-Larmer, editors. 1999. The consensus building handbook. Sage, Thousand Oaks, California, USA. 